University of Nebraska - Lincoln

DigitalCommons@University of Nebraska - Lincoln

Faculty Publications, Department of Psychology

Psychology, Department of

May 2006

\title{
Emotion and the Law: A Framework for Inquiry
}

Richard L. Wiener

University of Nebraska-Lincoln, rwiener2@unl.edu

Brian H. Bornstein

University of Nebraska-Lincoln, bbornstein2@unl.edu

Amy Voss

University of Nebraska-Lincoln

Follow this and additional works at: https://digitalcommons.unl.edu/psychfacpub

Part of the Psychiatry and Psychology Commons

Wiener, Richard L.; Bornstein, Brian H.; and Voss, Amy, "Emotion and the Law: A Framework for Inquiry" (2006). Faculty Publications, Department of Psychology. 181.

https://digitalcommons.unl.edu/psychfacpub/181

This Article is brought to you for free and open access by the Psychology, Department of at DigitalCommons@University of Nebraska - Lincoln. It has been accepted for inclusion in Faculty Publications, Department of Psychology by an authorized administrator of DigitalCommons@University of Nebraska - Lincoln. 
Published in Law and Human Behavior 30 (2006), pp. 231-248. Copyright (C) 2006 American PsychologyLaw Society/Division 41 of the American Psychological Association; published by Springer Verlag. Used by permission. http://www.springerlink.com/content/1573-661X/

\title{
Emotion and the Law: A Framework for Inquiry

\author{
Richard L. Wiener • Brian H. Bornstein • Amy Voss \\ University of Nebraska-Lincoln
}

Published online May 31, 2006

\begin{abstract}
This paper draws on research in social and cognitive psychology to show how theories of judgment and decision making that incorporate decision makers' affective responses apply to legal contexts. It takes 2 widely used models of decision making, the rational actor and lens models, and illustrates their utility for understanding legal judgments by using them to interpret research findings on juror decision making, people's obedience to the law (e.g., paying taxes), and eyewitness memory. The paper concludes with a discussion of the advantages of modifying existing approaches to information processing to include the influence of affect on how legal actors reach judgments about law and legal process.
\end{abstract}

Keywords: Emotion, Legal decision making

How should psychological scientists think about emotion in the law? Although the study of affect and motivation in information processing models has captured the attention of many who think about social cognition, judgment, and decision making (see Brewer \& Hewstone (2004) for a review of current ideas), the impact of this thinking has only begun to make its way into research and theory in legal psychology. The special edition of Law and Human Behavior on this topic showcases some of the more recent attempts to apply emotion to legal analysis and psycholegal research (Bornstein \& Wiener, 2006), but even these articles leave open the more general problem of how psychological researchers can and should infuse observer affect into their studies of legal decision making. Here, we offer an approach that mixes theories of emotion into standard models of judgment and decision making and then show how our approach can offer new insights into understanding some traditional areas of legal psychology. The paper begins by tracing some distinctions that social cognitive researchers make about emotion and then proceeds to use them to modify two existing models of judgment and decision making. We show how infusing affect into the rational actor and lens models of decision making can offer new and interesting

Corresponding author: R. L. Wiener, 238 Burnett Hall, University of Nebraska-Lincoln, Lincoln, NE 68188; email: rwiener2@unl.edu 
insights with examples from jury decision making, obedience to the law, and eyewitness identification. We conclude by arguing that mixing affect into studies of legal decision making promises to be a heuristic process in the most general sense of legal decision making.

\section{Judgment and decision making in the law is emotional}

This paper does not offer a new model of legal decision making. Instead, it examines two older approaches, the rational actor and the lens models (see Hastie \& Dawes (2001)) suggesting ways in which we can stretch and pull them to accommodate the very real but often neglected reality of the emotional context that precedes, surrounds, and follows judgments and decisions in law and legal process. Although psycholegal researchers have applied cognitive, developmental, social, and most recently social cognitive theories to study the manner in which judges, jurors, attorneys, police, litigants, and citizens make decisions and judgments required, or at least, encouraged in the law, they have done so largely in an emotional vacuum. Perhaps it is because the law demands an objective standard for evaluations of responsibility, culpability, liability, punishment, and damages that legal psychologists studying judgment and decision making have all but ignored emotion, mood, and motivation in their work. Although there is an occasional conceptual nod in the theoretical literature or an equally rare effort at measuring or manipulating affective variables in the empirical literature, most studies of legal decision making treat emotion (and motivation) as unwanted intruders in the objective world of weighing inputs and throughputs to reach one of a very few permissible outputs.

This state of our science might ring untrue to the experts in the field (i.e., judges, lawyers, police, and litigants) because they naturally expect emotion to be an important factor in how people make legal judgments. If so, then one potential answer to these skeptics could be that the emotional and motivational states that people experience have little influence on their evaluations of facts and evidence, and that such states do not alter the way in which people understand and apply the law. However, in its current state, our science has precious little to say about the importance of mood and emotion in the problems of law and legal process. At the same time, other judgment and decision researchers have acknowledged the role of affect in their empirical work and have modified existing models to take into account the possible influence of mood and emotion in human choice and inference (for reviews, see Brewer \& Hewstone, 2004; Hastie \& Dawes, 2001). Before we apply either the rational actor model or the lens model to the problem of legal judgment and decision making, we find it useful to consider some very specific ways in which the affective world of decision makers might influence their conclusions.

\section{Anticipated and experienced emotion}

First, judges, jurors, attorneys, experts, eyewitnesses, litigants, police, and everyday citizens anticipate the emotional consequences (both pleasant and unpleasant) that are likely to follow from their choices, decisions, and inferences. They undoubtedly are aware of the impact that their judgments could have not only for themselves but also for the other significant legal actors that define the context in which the decision makers reach their conclusions. Research shows that people choose those outcomes that they believe will produce the most positive emotional consequences for themselves. For example, Mellers and her colleagues (Mellers, 2000; Mellers, Schwartz, Ho, \& Ritov, 1997; Mellers, Schwartz, \& Ritov, 1999) have demonstrated that in a variety of decision tasks (e.g., financial gambles, seeking feedback on test scores and pregnancy tests), anticipated pleasure supplemented the logic of rational decision making (i.e., expected utility logic) in real world and laboratory choices. Translating to the current prob- 
lem, people who anticipate experiencing a pleasant mood after making a legal choice or judgment will be more likely to choose in favor of the outcome that they believe will produce that emotional state. Those who anticipate experiencing an unpleasant mood (such as regret, anger, or disappointment) will be less likely to choose the same outcome. It is likely that legal actors also take into consideration the emotional outcomes that others are likely to experience as a result of their decisions. This suggests that the emotions that legal decision makers anticipate when they contemplate their conclusions will mediate the effect of evidence, information, and data on their final deliberations and judgments. Prior research shows that the influence of anticipated emotion can override rational decision making when the mood analysis disagrees with a purely cognitive rule (Shiv \& Fedorikhin, 2002).

Even more radical, in the sense that it deviates sharply from an objective model of legal choice, is a second hypothesis that emotions experienced at the time of a judgment can help determine decisions (Loewenstein, Weber, Hsee, \& Welch, 2001) and direct behavior, just as anticipated emotion does. The experienced emotion need not result from the stimuli before the decision maker; rather, it can arise from internal or external factors incidental to the task. However, it is difficult to override the emotional influence of vivid materials in legal contexts (Bornstein \& Nemeth, 1999); therefore, only rare individuals can ignore their own emotional reactions to the facts in a specific civil or criminal dispute. It follows that researchers who study the role of emotion in legal decision making must consider both the preexisting emotional state of the evaluator as well as the emotion that decision makers naturally experience after reviewing the facts of an actual or potential dispute. Most importantly, the emotional inducements that unavoidably accompany the facts in a legal dispute most likely interact with the preexisting emotional state of the decision makers, which themselves result from either dispositional characteristics of the evaluators or the situational context in which the decision makers find themselves. The problem of experienced emotion at the time of the decision is indeed a complicated one (see, e.g. Feigenson \& Park, 2006; Maroney, 2006).

Until recently, the social psychological research literature suggested that people engage in more thorough and systematic information processing when they experience negative, compared to positive, mood states (Batra \& Stayman, 1990; Bless, Bohner, Schwarz, \& Strack, 1990; Mackie, Asuncion, \& Rosselli, 1992; Mackie \& Worth, 1989; Murray, Surjan, Hirt, \& Surjan, 1990; Schwarz, 1990; Schwarz, Bless, \& Strack, 1991; Sinclair \& Mark, 1992; Worth \& Mackie, 1987). However, some studies report findings contrary to the "negative mood" effect (Isen, 1993; Parrott \& Sabini, 1990; Wegener, Petty, \& Smith, 1995). In part, to explain these findings, Lerner and Keltner developed appraisal-tendency theory, in which cognitive appraisals differentiate between emotions beyond the simple valence dimension (i.e., positive vs. negative mood). It suggests that the specific emotions that decision makers experience through direct contact with the "to be judged" stimuli, or that they incidentally bring to the task, impact judgments and decisions. Accordingly, emotions focus attention, memory, and behavior about the current environmental task and carry over to shape responses to novel situations. Among the studies of cognitive appraisal effects in social judgments (Lerner \& Keltner, 2000, 2001; Lerner, Gonzalez, Small, \& Fischhoff, 2003), those that are most central to the current paper are Smith and Ellsworth's (1985) early work and Tiedens and Linton's (2001) later application.

Smith and Ellsworth (1985) asked participants to recall 15 events in their lives in which they experienced each of 15 emotions, and then to rate those events on emotional dimensions. Factor analysis and multidimensional scaling retrieved six orthogonal dimensions from the emotion ratings. These emotion appraisal dimensions were pleasantness, anticipated effort, certainty, attentional activity, self-other responsibility, and situational control Smith and Ellsworth. In a series of four experiments, Tiedens and Linton (2001) extended these findings by using two of these dimensions, pleasantness and certainty, to untangle the mood and judgment liter- 
ature with its inconsistent negative mood effect. Some pleasant emotions (e.g., happiness and contentment) and unpleasant emotions (e.g., anger and disgust) convey a sense of certainty, whereas other pleasant emotions (hope and surprise) and unpleasant emotions (fear and worry) convey uncertainty. Still other emotions (sadness) fall in the middle of the certain-uncertain continuum. In one study, participants wrote about an autobiographical event that they remembered and mentally relived, which made them feel anger, contentment, worry, or surprise. This emotional induction crossed the variables of emotional valence and certainty. Later, participants read an essay ostensibly written by a student or an expert professor, which argued that grade inflation was on the rise and therefore professors should evaluate college students' performances more critically. Results showed that relative to the student essay, the expert essay persuaded students more, but only in the certain emotion conditions (anger and contentment), and not in the uncertain emotion conditions (worry or surprise). There were no differences for the pleasantness of the emotions. This and three other experiments demonstrated that specific mood states determine people's level of certainty, such that when certainty is low they will exert more effort in processing (to regain a sense of certainty) and will not be influenced by surface or stereotypical cues. However, when their levels of certainty are high they process heuristically so that surface and stereotypical cues are more influential what Eagly and Chaiken, 1993, call the "sufficiency threshold hypothesis"). Translating to legal decision making, we anticipate that surface or heuristic thinking should flourish when legal actors are certain and process less systematically. Therefore, heuristic thinking should be elevated for angry legal actors (high in certainty) relative to fearful ones (low in certainty) (Smith \& Ellsworth, 1985).

\section{Affect infusion model, affect as information, and affect as primes}

Although we find the distinction between anticipated and experienced emotion a useful one for understanding legal decision making, other distinctions offer analogous but slightly different approaches. Forgas developed a model that incorporates mood states into decision processes, which could influence the outcomes of judgment and choice in legal contexts. The Affect Infusion Model (AIM) predicts mood effects for tasks requiring open thinking and the interpretation of ambiguous information (i.e., almost all legal judgments and choices) as compared to those that are routine or guided by other goals. As a result, the AIM predicts that affect infusion will occur most during heuristic and substantive processing and least during direct access and motivated processing (Forgas, 1995).

One way in which affect infuses evaluations during substantive processing is through the indirect route of affective priming. Affective priming occurs when affect influences attention, encoding, retrieval, or associative processes (Forgas, 1995). There is an abundance of research that supports affective priming and demonstrates mood congruent effects in evaluations of social behavior (Forgas, Bower, \& Krantz, 1984), persuasive messages (Petty, Gleicher, \& Baker, 1991), and causal inferences (Forgas, Bower, \& Moyan, 1990). For example, Forgas et al. (1990) demonstrated that happy participants were more likely than were sad participants to credit success to internal causes and credit failures to external causes. The influence of mood upon interpretations of causality is particularly relevant to legal decision making (e.g., negligence judgments) in which litigants, attorneys, judges, and ultimately jurors attribute responsibility to injurious conduct.

With regard to heuristic processing, the AIM relies on affect-as-information theory to explain how affect infusion occurs during heuristic processing. The affect-as-information theory posits that affect influences evaluations when evaluators, lacking cognitive capacity, simply ask themselves "How do I feel about it?" instead of computing a judgment on the basis 
of features of the target (Schwarz, 1990). As a result, individuals may mistake feelings because of a preexisting state as a reaction to the target Schwarz. In a classic study, Schwarz and Clore (1983) found that participants interviewed on a sunny day were in better moods and were more likely to give positive evaluations than were participants interviewed on a rainy day, if the interviewers did not make participants aware that the true source of their moods was the weather. Another theory that explains the influence of emotion upon evaluations closely related to affect-as-information is the affect heuristic (Slovic, Finucane, Peters, \& MacGregor, 2002), which also proposes that affective associations are stored in memory for later use in decision making. In this manner, the affect heuristic provides a resource for individuals to consult in the process of making decisions. This affective route can be faster and easier than weighing the pros and cons of legal arguments.

Evidence supporting this theory has demonstrated that emotion can directly influence risk evaluations. Previous research has found that perceptions of risks and benefits are positively correlated in the real world but individuals perceive risks and benefits as negatively correlated. Further, the extent to which individuals perceive this inverse relationship is correlated with the strength of the positive and negative affect that is associated with the target activity (Alhakami \& Slovic, 1994). Building on this research, Finucane, Alhakami, Slovice, and Johnson (2000) provided participants with four kinds of information designed to manipulate affect by increasing or decreasing perceived benefits and risks. Results demonstrated that participants provided with information about the benefits of an activity in turn had increased positive affect and ultimately this led to decreased perceptions of risk. By contrast, participants provided with information about the risks of an activity developed negative affect, which in turn led to increased perceptions of risk.

From a legal perspective, we have found in our own work on judgments about sexual harassment that the affective heuristic explains well the effects of incidental (induced) emotion, as well as emotion arising from the to-be-judged stimulus material. Voss and Wiener (2006) examined how emotion influenced participants' use of extra-legal factors (i.e., complainant's behavior unrelated to the alleged harassing episodes) and legal factors (i.e., the unwelcomeness, severity, and pervasiveness of the conduct) when determining if harassment had occurred in videotape reenactments of two legally influential sexual harassment cases, Faragher v. City of Boca Raton (1998)and Rabidue v. Osceola Refining Co.(1986). In Study 1, participants rated their experienced emotion after viewing the videotape but in Study 2 we induced participants to feel anger, fear, or no emotion by writing about an autobiographical event. In both studies, participants viewed two videotapes depicting workplace situations and determined if sexual harassment had occurred. Depending upon the condition, the complainant in the first videotape behaved either in an aggressive or neutral manner toward other workers (prime), whereas the complainant in the second videotape always behaved in a neutral manner. We predicted that the priming manipulation in the first videotape would carry over or prime perceptions of the second tape. The extent of the priming effect was an indication of participants' reliance upon the complainant's behavior to decide if sexual harassment had occurred.

Results for both studies indicated that as participants experienced increased levels of emotion, they relied less on both the legal factors and the prime in making their decision. Specifically, prime and emotion interactions revealed that increased ratings of harassment were associated with the hostile prime as compared to the neutral prime for those participants experiencing low levels of emotion. We interpreted these results to suggest that participants experiencing low levels of emotion and exposed to the hostile prime were more upset by the prime (the complainant's behavior) and this increased the complainant's credibility. In other words, the complainant's hostile behavior led participants to take her complaint more seriously and as a result rate the likelihood of harassment as higher. By contrast, participants viewing the hos- 
tile complainant who were already experiencing high levels of emotion did not make this interpretation because their emotion levels were already high and their perceptions of harassment were similarly elevated. Therefore, the allegations only increase perceptions of the likelihood of harassment when they are accompanied by an emotional impact. Observers seemed to refer to their own emotional arousal level to determine whether a hostile work environment existed in the workplace. This emotional impact can come in the form of incidental inducement, reaction to the episode, or in reaction to a hostile complainant herself.

\section{Incorporating affect into legal decision making models}

There is indeed a rich literature on affect in social cognition, which researchers may draw upon to enhance their insights of information processing in the law. However, to bridge the literatures in social cognition and legal psychology we need mechanisms to tie together affect and judgment in ways that offer insights about legal processes. Regardless of whether legal psychologists adopt the anticipated versus experienced emotion didactic, the AIM, the primed affect construct, or the affect as information analysis, it is necessary to fit affect theory and findings into existing information processing models of legal decision-making. The two approaches at the foundation of legal decision making, which offer platforms for understanding emotion in the law are the rational choice model and the lens model (Hastie \& Dawes, 2001).

The rational choice model

Korobkin and Ulen $(1998,2000)$ in their analysis of the law and economics movement identified as the chief tenets of the rational choice approach the principle that people respond to incentives, and that skillful policy makers can use the law to encourage socially desirable conduct and discourage the undesirable. People acting under the boundaries and constraints of law weigh the costs and benefits of following the law against the same for not following the law. Further, the law encourages efficient use of social resources and discourages the wasteful use of those same resources. In the recent past, legal scholars used the efficiency principle to suggest similarly that tort and other civil law claims achieve settlements that favor those for whom the gains are most valued, and disfavor those who value the gains least (Landes \& Posner, 1987). Landes and Posner used the logic of economics to illustrate how the theory of incentives and the principle of efficiency justify the existing common law rules, which make up contemporary tort law doctrines. Other law and economics authors use these same basic principles to explain and justify areas of jurisprudence in both the criminal and civil law in accordance with accepted doctrine Korobkin and Ulen (Monahan \& Walker, 2002, p.26).

Rational choice theory is the driving force of the law and economics movement. According to decision theorists Hastie and Dawes (2001, p. 18), a rational choice must meet four criteria. First, a decision maker bases a rational choice solely on assets at the time of the decision, which include not only financial assets but also the nature of the decision maker's "physiological state, psychological capacities, social relationships, and feelings." The decision maker values these assets and acts in ways to increase, or at least, maintain them. Second, the rational decision maker takes into consideration the consequences of choices with respect to the status of the decision maker's extant assets (physical and psychological). Third, under conditions of uncertainty the rules of probability describe the way in which decision makers evaluate the likelihood of consequences that will influence the distribution of these assets. This is not to suggest that decision makers apply formal calculations to reach optimal outcomes. Instead, decision makers are intuitive statisticians whose subjective probability estimates are congruent with the basic and funda- 
mental tenets of probability theory. Finally, the driving force in decision-making is adaptation. Accordingly, decision makers reach decisions within the constraints of the probabilities of consequences and the values or satisfactions that stem from the possible outcomes of choice. In the language of Judge Posner, "man is a rational maximizer of his ends" (Posner, 1997, p.24).

The expected utility model of rational choice puts more meat on the bare bones of the rational maximizer. Korobkin and Ulen (2000) write about a decision in which there are two choices, each with an uncertain probability, and the task for the decision maker is to select one choice over the other. Each choice leads to multiple possible outcomes and each of those outcomes is associated with a change in assets that is either valued or devalued. The choice would be simple if the consequences of the outcomes were certain but in the real world, the consequences are usually uncertain, best described as probability statements associated with the outcomes and their consequences. According to decision analysts, the rational solution to selecting a choice is to estimate the expected utility of each choice and then select the choice with the highest expected utility. In other words, the adaptive approach is to conduct a cost-benefit analysis for each choice and then adopt the choice that maximizes the likelihood of a positive change in one's assets. ${ }^{1}$

The Hastie and Dawes (2001) approach to rational choice broadens the rational choice model to include the role of mood, affect, and emotion broadly defined in conscious and unconscious choice strategies. In other words, the decision maker estimates the utility of the potential outcome, in part, by weighing the likelihood of each outcome by the anticipated emotional reaction (positive or negative) that the decision maker expects to experience with each outcome. The decision maker's own reaction will be a function of experience with the outcomes in question, experience with similar outcomes, and estimates of the affect associated with these outcomes for both the self and others. In fact, one could contemplate a judgment strategy that balanced the emotion that the decision maker anticipated for the self with the emotion that the decision maker anticipated others would feel after the judgment. In sum, decision makers should avoid choices that have high likelihoods of resulting in negative affect in favor of those with high likelihoods of producing positive affective outcomes. From the point of view of the legal psychologist, it matters little whether this modified rational choice approach deviates far enough from the traditional expected utility model to constitute a new model. Its contribution results from the extension of an existing rational logic model to include in the decision maker's judgment calculus the reality of the affect that most certainly accompanies legal judgments and decisions.

Consider two examples of the usefulness of such an "accommodated rational actor" model. First, we review a jury decision-making study in which a woman killed her husband and offered a self-defense theory based upon the fact that the deceased had regularly battered the woman for a number of years (Schuller \& Rzepa, 2002). The authors set out to test the effect of battered woman syndrome on jury verdicts. Although prior research Schuller and Hastings (1996) demonstrated that jurors were more lenient toward a woman defendant when her case included expert testimony about the battered woman syndrome, some legal commentators recommend caution in using the defense. They argue that if the defendant's history of conduct is active and not passive, this defense could backfire by showing a stark inconsistency with the helplessness that is central to battered spouse syndrome (Dobash \& Dobash, 1984; Fischer, Vidmar, \& Ellis, 1993). In addi-

\footnotetext{
${ }^{1}$ Korobkin and Ulen (2001, p. 1051) formalize the rational actor model when they write, "The actor will presumably attach a utility to each possible outcome $\mathrm{U}(\mathrm{O} 1), \mathrm{U}(\mathrm{O} 2)$, and so forth, along with a probability of each outcome occurring p1, p2, and so on." The decision maker then calculates the expected utility (EU) for each outcome or consequence, "EU (uncertain action) $=\mathrm{p} 1 \mathrm{U}(\mathrm{O} 1)^{1}+\mathrm{p} 2 \mathrm{U}(\mathrm{O} 2) \ldots \mathrm{pnU}(\mathrm{On})$ " and selects the choice with the greatest expected utility. The utilities that the decision maker attaches to each outcome are "personal values" that reflect changes in assets that result from choices and their outcomes or consequences (Hastie \& Dawes, 2001).
} 
tion, even if the defendant acted consistently with the battered woman pattern, the use of the term could offer a negative view of the defendant as dysfunctional and possibly emotionally disturbed (Browne, 1987; Crocker, 1985; Schneider, 1986). Although Schuller and Hastings challenged some of these beliefs with empirical data, prior to Schuller and Rzepa's (1996) work, we knew very little about the way in which jurors reach decisions in cases that use the battered woman defense. It should be clear to the casual observer that expected emotion in the form of sympathy for the defendant could play a critical role in battered women defense cases.

Schuller and Rzepa (2002) manipulated the availability of the battered spouse defense by offering only half the mock jurors expert testimony about battered woman syndrome, in which the expert defined the condition as a special case of Posttraumatic Stress Disorder with symptoms of avoidance, anxiety, and memory disorders. The testimony also depicted the Cycle Theory of Violence and the Theory of Learned Helplessness with Walker's (1984) stages of "tension building," "acute battering," and "loving contrition." The expert described the syndrome and testified that those women who were long-time victims of battering would show heightened fear and would be more likely to experience imminent danger when confronted by an angry spouse. Those mock jurors who did not receive this testimony still had the option of acquitting the woman on the grounds of self-defense but did not have any reason to anticipate that the defendant had heightened fear and anxiety in the presence of her spouse.

Half the participants read a case summary about a passive woman who did nothing to defend herself against her husband's battering (i.e., a woman whose conduct was consistent with the battered woman syndrome), whereas the other half learned that the defendant had actively (verbally and physically) defended herself against the batterer. The active woman broke her husband's arm with a baseball bat after a prior attack and on another occasion, she pointed a rifle at his head and challenged his manliness after he had threatened her. Most importantly for the current discussion, half the jurors received radical nullification jury instructions that told them that the law was not controlling and that they could ignore it if they thought the law would produce an unfair or unjust verdict in this case (Horowitz, 1988; see also Horowitz, Kerr, Park, \& Gockel, 2006). The other half read only the regular instructions, which all the jurors received. These instructions defined the burden of proof, standard of proof, and elements of the Canadian law for second-degree murder, manslaughter, and self-defense (justified if the defendant had a "reasonable apprehension of death or bodily harm and believed on reasonable grounds that she could not otherwise protect herself" p. 656).

Jurors completed a lengthy posttrial questionnaire, which among other questions, asked about the verdict (guilty of second-degree murder, manslaughter, or not guilty/self defense), sympathy for the defendant, psychological stability of the defendant, and evaluations of the expert testimony. The most interesting and important finding for the current discussion is the interaction of expert testimony and jury nullification instructions on verdict. Specifically, more jurors in the battered woman testimony condition reached self-defense verdicts than did those without the testimony, but they did so only when they operated under the radical nullification instructions. One could argue that those jurors whom the researchers encouraged to disregard the law felt sympathy for the defendant and therefore reached a not guilty verdict. These jurors may have anticipated feeling negative emotions (regret and perhaps guilt) if they had found the defendant guilty in the nullification condition. To avoid those negative feelings, these jurors may have favored a selfdefense verdict over a second-degree murder or manslaughter verdict. In fact, Schuller and Rzepa (2002) reported a parallel two-way interaction between expert testimony and nullification instructions, such that those exposed to battered woman expert testimony felt more sympathy toward the defendant only when they operated under radical nullification instructions. Taken together, these results suggest that the participants in this experiment who received nullification in- 
structions and expert testimony about battered woman syndrome felt sympathy for the defendant. In accordance with the rational actor model modified for affective outcomes, jurors may have reasoned that there was a high likelihood that if they found the woman guilty, their own sympathy would have turned into the negative feelings of regret and self-guilt. These jurors may have acquitted the defendant to avoid these negative feeling state outcomes.

This mechanism is, of course, not what the law of self-defense requires. If the jurors followed the letter of the law and were convinced by the self-defense appeal, then they should have found the defendant not guilty in both the nullification and traditional instruction conditions. Under both types of instructions, the expert testimony should have been equally effective in convincing the jurors that the defendant was in reasonable apprehension of death or bodily harm, and that without a violent response she could not otherwise have protected herself. Instead, the jurors seemed to reach conclusions based upon the sympathy that the nullification instruction intensified and those jurors made subsequent efforts to avoid the likelihood of experiencing a negative affective outcome.

Consider a second study in which researchers collected data to test the rational actor model more directly as it influences the decision whether or not to cheat on one's income taxes (Wenzel, 2004). Here, the decision maker must decide whether to comply with the law and pay a certain amount of money (one's tax bill) with a probability of monetary loss equal to 1.00 or to take a chance and evade paying all one's taxes. There is, of course, a probability less than 1.00 that government accountants will detect the evasion and charge the payer the full amount plus a penalty. On the other hand, there is a probability that the tax evasion will be successful (1.00 minus the likelihood of being caught) in which case the payer will gain the difference between paying the full amount of taxes and the amount that the payer actually sent to the government. One could apply an expected utility analysis (see earlier) and based upon the estimated probabilities and expected tax bills predict whether any given individual would pay the full bill or attempt tax evasion.

Under such a system, the model predicts that tax compliance would increase as a function of the subjective certainty of detection and the size of the penalty that the system imposes for cheating. Therefore, deterring tax evasion would increase with more certain detection and greater monetary penalties for cheating. As Wenzel (2004) points out, the literature generally supports the deterrent effect of increasing certainty of detection and the size of penalties, but with the former effects more consistent than the latter (Kinsey \& Grasmick, 1993; Varma \& Doob, 1998) see Wenzel for a complete review of this literature). The asymmetry in these findings suggests researchers need to take into consideration other factors (especially with regard to valuing outcomes) in their models of tax compliance. Some data show that norms of morality and fairness (Scott \& Grasmick, 1981; Wenzel, 2002) seem to moderate the effects of the expected utility logic especially when the metric of the outcomes remains economic self-interest Wenzel. Although Grasmick and colleagues have demonstrated that emotion in the form of perceived guilt is one factor that lowers the valued outcome of successful tax evasion (Grasmick \& Bursik, 1990; Grasmick \& Scott, 1982; Scott \& Grasmick, 1981), the more current investigations have moved away from measures of emotions in favor of measures of justice norms. Although we applaud the consideration of justice norms in legal decision-making models, we wonder if researchers should also include emotional mediators in their work.

Wenzel (2004) distinguished between two types of justice norms, personal norms (i.e., individuals' standards of right and wrong, which they gain through identification with a group) and social norms (i.e., a group's standards of right and wrong imposed on an individual who does not necessarily identify with the group). Wenzel argued that when officials catch taxpayers cheating, the cheaters suffer greater social costs when they are aware of the social norms against cheating even if they have lower personal norms against dishonesty. Taxpayers who 
demonstrate higher social norms against cheating will anticipate greater negative affect (i.e., shame and embarrassment) at the prospect of their detection. As a result of the greater costs, Wenzel predicted social norms would moderate the deterrent effects of individuals' perceptions of higher certainty of detection, higher likelihood of sanctions, and more severe sanctions. At the same time, he predicted that people with higher personal norms would simply not cheat because of their own internalized values. He expected deterrence effects only for individuals who held low personal norms against cheating.

To test these predictions, Wenzel (2004) examined the self-reports of over 1400 Australian respondents who had completed Braithwaite's (2000) Community Hopes, Fears, and Action survey. Eleven items that pertained to underreporting paid income, underreporting nonpaid income, and exaggerating deductions together measured tax compliance. Respondents rated on several measures the likelihood of being caught cheating on a tax evasion scenario, the likelihood of sanctions for cheating on that scenario, and the severity of the sanctions that might result. A factor analysis produced one factor measuring the likelihood of sanctions and another measuring the severity of the sanctions. Finally, Wenzel measured social norms with questions asking the respondent what most people think about honesty in paying taxes and measured personal norms with questions asking what the respondent thought about honesty with respect to the same issues.

Main effects from a regression analysis showed decreased tax evasion on the self-report compliance measure with increased ratings of likelihood of sanctions, severity of sanctions, and personal norms on the scenario task. Most importantly for the purpose of the present discussion, perceived severity of the consequences interacted significantly with social norms in predicting tax evasion, such that increases in perceptions of the severity of the consequences were negatively related to the likelihood of tax evasion for those with strong social norms against cheating but not for those with weak social norms. Further, a significant interaction between severity of consequences and personal norms showed the exact opposite effect, severe sanctions were negatively associated with tax evasion, but only for those with weak personal norms. One interpretation of these findings is that the shame and embarrassment that taxpayers anticipate for getting caught cheating tips the scales against cheating for those with strong social norms because they wish to avoid the experience (reduce the likelihood) of those feelings in the future. Wenzel (2004, p. 561) concluded, "Sanction severity was only negatively related to tax evasion, and seemed to have a deterrence effect, when norms of tax honesty are perceived as strong, but where the norms were not internalized or incorporated into one's social self through a process of social identification." We would argue that people with strong social norms but weak personal identification with those norms are most likely to anticipate the embarrassment and shame that they would feel if they were caught cheating on their taxes and did not do so to avoid those negative feelings. In other words, the probability of experiencing negative affective outcomes (embarrassment and shame) were so high for these individuals that the expected utility of cheating decreased significantly enough to deter them from practicing tax evasion.

Unfortunately, this correlational data set did not allow any causal interpretations and it did not measure directly the participants' shame and embarrassment. Of course, the latter issue is our interest and not the interest of the original researcher. Still, we suspect that the lack of emotional measures in this research and other studies results from researchers' willingness to accept the rational choice model without considering the role that anticipated emotion can play in its calculus. Although we cannot be certain if anticipated emotion mediated Wenzel's (2004) effects, we are certain that including emotional constructs in the expected utility model and including measures of emotion in legal decision-making studies have great potential to produce important and interesting mediators in legal psychology. 


\section{The lens model}

A second major model for judgment and decision making employs human perception as its basic analogy, rather than an economic model, to describe the ways in which decision makers actually make judgments and decisions. The formal depiction of legal judgments that the lens model affords offers a way to isolate the likely influence of experienced affect on legal judgment and decision making. The lens model is a generally accepted framework for capturing the values and weights that decision makers assign to informational inputs (Hastie \& Dawes, 2001, p. 49). Although there are a number of statistical procedures that researchers can and do use to measure the parameters that make up the lens model framework, the basic relationships that it describes between judgment inputs and outputs offered at a conceptual level go a long way to illustrate some of the mechanics of how people use environmental input to reach specific judgments and decisions. It is not difficult to expand the lens model to take into consideration the role of affect experienced at the time of the judgment on legal decision making.

The lens model is a conceptual framework for describing the relationship between the information or cues in the external world, their representations in memory, and the judgments or decisions that people reach by considering those cues (Hammond, 2000a, 200b; Hastie \& Dawes, 2001). The name of the framework comes from the realization that people draw inferences about the external world, which they cannot really ever know, from imperfect sources of information. It is through this imperfect perceptual lens that decision makers ultimately make judgments and predictions. Figure 1 is a conceptual replication of the model, borrowed from Hastie and Dawes and others before them (e.g. Brunswik, 1952).

One legal context in which researchers have examined stressful arousal is eyewitness memory (see, e.g. Stein, Ornstein, Tversky, \& Brainerd, 1997), where researchers have shown stress but not specific emotions have generally negative effects (Deffenbacher, Bornstein, Penrod, \& McGorty, 2004). We illustrate the parameters of the lens model with an example from eyewitness memory in a criminal context. Here, an investigator asks whether a witness to an illegal activity observed specific actions and events that could have made up the illegal action. Although the lens model approach is useful for analyzing a number of eyewitness effects during the encoding, postevent, and retrieval stages, we focus on the misinformation effect or the incorporation of suggested information that the observer did not actually see during the encoding process (see, e.g. Gerrie, Garry, \& Loftus, 2005), for review). More specifically, we use the lens model to examine how experienced affect influences the manner in which a witness might utilize cue probabilities to judge whether they observed specific actions, events, and situations during the encoding process. Figure 1 applies the lens model to the misinformation effect in eyewitness identification.

Loftus (1979) conducted a series of influential experiments in which misinformation was introduced to eyewitnesses in the form of post-event misleading questions, very much like those that an investigator might ask a witness after the onlooker observed a criminal act. The issue for the witness is to judge the likelihood that each of the cues (some gathered during encoding and others gathered post-event through investigator suggestion) was actually part of the "to be described event." The work of Loftus and others showed that people tended to confabulate their reports infusing the misinformation into their accounts of the actual crime scene (Loftus, Donders, Hoffman, \& Schooler, 1989). Although several authors discuss the implications of the misinformation effect in legal decision making especially during the investigatory and adjudication processes (Cutler \& Penrod, 1995; Ross, Read, \& Toglia, 1994; Wells \& Loftus, 2003), others qualify the importance of the phenomenon because they do not always find strong misinformation effects. Some suggest that the misinformation effect is mutable and depends upon the strength of the memory traces involved (Pezdek \& Roe, 1995; Reyna \& Loyd, 1997). Some re- 


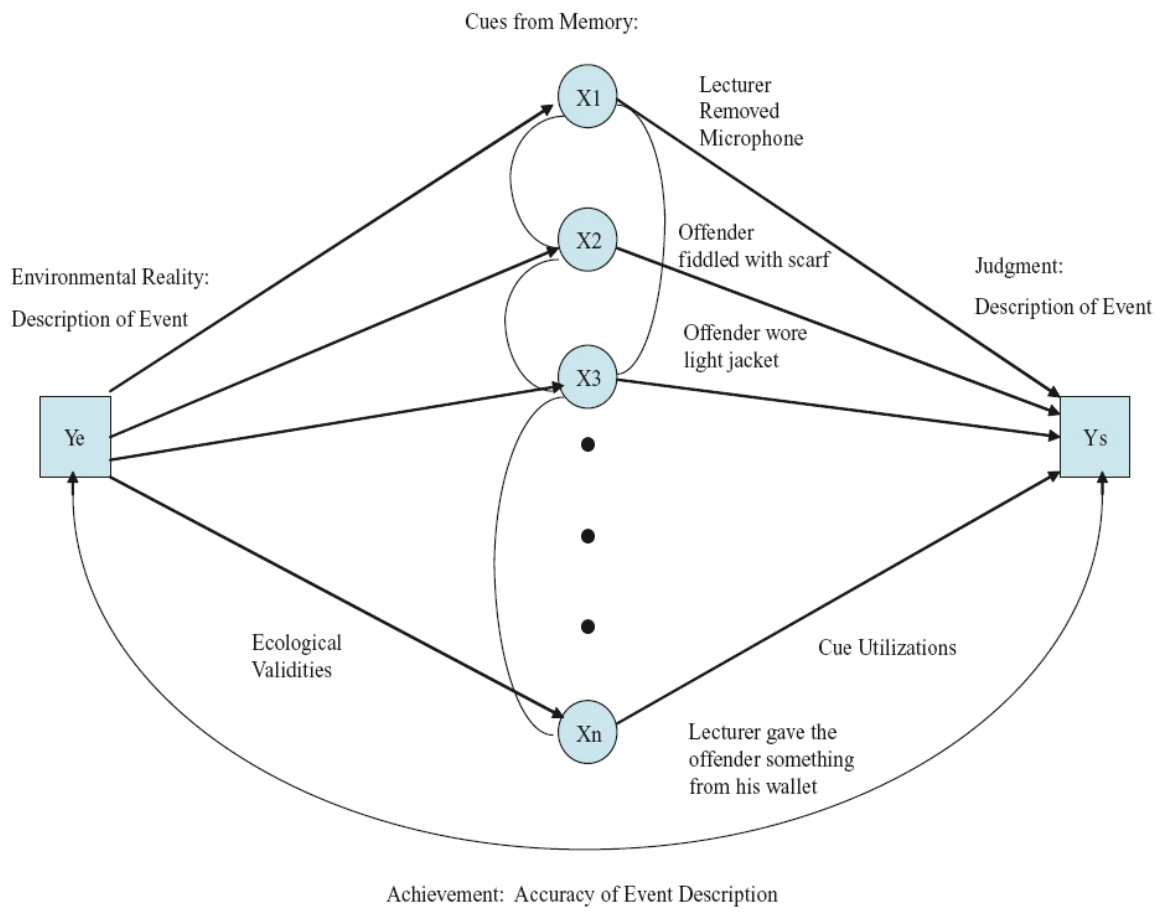

Fig. 1 The lens model as a description of eyewitness's description of a crime scene

searchers suggest that the effect is largely a problem of information source monitoring (Lindsay \& Johnson, 1989a, 1989b) and still others view the problem as one that is most problematic when the observers are subject to social suggestion (McCloskey \& Zaragoza, 1985). In any event, there is continued interest in the misinformation effect and in identifying both moderators and mediators for its occurrence (Forgas, Laham, \& Vargas, 2005).

The lens model (Hammond, 2000a, 2000b; Hastie \& Dawes, 2001) suggests a variable relationship among informational cues that eyewitnesses gather from the environment as they try to judge the likelihood that each cue was actually part of the original crime scene. Figure 1 depicts a judgment task for an assault that Forgas, Laham, and Vargas (2005, Experiment 2) staged in a university lecture hall to study the impact of experienced affect on the misinformation effect. Here, a female intruder walked into a lecture hall and assaulted the lecturer. The left side of the diagram shows the distal property in the environment that the witness seeks to describe, and the right side of the diagram reflects the psychological processes that result in a final judgment about the assault. There was a staged (ostensibly a real) assault and some of the cues associated with it in the observers' memories came from their observation of the event (i.e., the lecturer removed the microphone as the offender approached and the offender fiddled with her scarf as she approached). However, other events were not part of the scene. Instead, the researchers provided misinformation as part of a post-event questionnaire that asked misleading questions, the information in italics (e.g., "Did you see the lecturer removing his microphone, as the woman wearing a light jacket moved towards him?" and "Can you remember the young woman fiddling with her scarf as the lecturer gave her something from his wallet?" p. 380). For other observers the post-event questionnaire asked only direct questions that described accurately events that occurred in the crime scene (e.g., "Did you see the lecturer re- 
moving his microphone as the woman approached?" "Can you remember the young woman fiddling with her scarf as the lecturer spoke to her?" p. 380).

For the eyewitness, the problem is to assess the cue validities (the likelihood that they actually came from the crime scene), form a final description of the crime scene, and accurately report that description to the experimenters (or to the police in a real investigation). The accuracy of the eyewitness depends upon two important parameters in the model, the ecological validities (i.e., the relationship between the external reality and cues stored in memory) and the cue utilization rates (i.e., the ability of the decision maker to review these cues and make judgments about the environmental reality of each). In this case, the eyewitness will only be able to make an accurate assessment if the evidence is accurate and the eyewitness is able to weigh the evidence appropriately (according to the ecological validity associated with the cues) to reach an accurate judgment. The questions of importance are, "What are the relationships between the recalled cues and the criminal event the way it actually occurred (ecological cue validities from Fig. 1)? Secondly, do the eyewitnesses reliably use this information to assess accurately the events that took place during the assault (cue utilizations from Fig. 1)?"

Forgas et al. (2005) hypothesized that the experienced affect of eyewitnesses at the time of their observations can play an important role as a moderator of the misinformation effect. Once again, Experiment 2 tested this by staging an unexpected assault on a lecturer in class and then presenting a brief questionnaire 1 week later that for half of the participants included direct questions and for the other half, misleading questions about the assault. However, just prior to introducing the post-event questionnaire, the researchers manipulated the mood of the participants (i.e., happy, neutral, or sad) by showing them one of the three videos pretested to produce those affective states. After the eyewitnesses participated in a series of distracter tasks, they answered several more questions about the crime scene. The questions included correct details (information that observers saw in the criminal episode but that they did not read about in the direct or misleading questionnaire), misleading details (i.e., incorrect information observers read in the misleading questionnaire but did not see in the criminal episode), and incorrect details (i.e., incorrect information that they did not see in the criminal episode or read about in the questionnaire).

Results showed a false alarm effect (Forgas et al., 2005) for participants in happy moods (induced through the video). Those who answered the misleading version of the brief questionnaire were more likely to describe the crime scene with misleading details as compared to happy participants who answered the direct version of the brief questionnaire. This was also true, but to a lesser extent, for those participants in neutral moods. Finally, for those participants in sad moods, the difference in false recall of misleading details was not significantly different in the misleading questionnaire version as compared to the direct questionnaire version. Forgas et al. interpreted these results to support one of their main hypotheses, that negative moods trigger accommodative processing focusing on the actual details of the environment, whereas positive moods trigger assimilative and constructive processing, which integrates existing knowledge, heuristics, and schematic thinking into task details.

A lens model interpretation suggests that participants in a happy mood were less sensitive to the ecological validities of the cues than were people in sad moods, or that those in happy moods did a poor job of cue integration relying more heavily on the misleading cues introduced post-event than those gathered at the time of the actual observation. That is, the happy moods and even neutral moods distorted the decision makers' representations of the images recorded in the lens. Use of the lens model to depict the judgment problem points out the importance of determining whether experienced emotion influenced the judgments through cue validity calculations, cue utilization rates, or cue integration operations and whether such in- 
fluences occurred consciously or unconsciously. Once again, although we are unable to answer these questions from the Forgas et al. data, we are able to ask some interesting and important questions about legal judgment and decision making by using a general judgment model to depict the task parameters. The lens model directs nicely the application of theories of affect to the problem of eyewitness identification.

\section{Affect and generic models of legal decision making}

We have tried to show with detailed examples how existing models can accommodate the role of affect in legal decision making. We now advocate for the use of these approaches to clarify how researchers ought to consider emotion when they study legal judgments and decisions. We conclude with a discussion of the advantages of modifying existing approaches to information processing to include the influence of affect on how legal actors make choices among options and reach judgments about law and legal process.

First, a general model approach to the study of affect in legal decision making allows for specific interactions among context, decision-maker attributes, emotional reactions and the law. As we have seen in each of the previous examples, expressing the legal decision-making problem as a general model pinpoints potential relationships in which context, affect, and decision-maker attributes moderate (and sometimes mediate) the effects of law on judgments and choices. Sometimes, merely viewing the decision problem as an expected utility problem or as a lens model makes salient some of the relationships among the elements of the task that were not readily apparent. For example, Schuller and Rzepa's (2002) results clearly show that the use of battered woman syndrome testimony as a viable defense, at least in a homicide case, requires that the jurors have a great deal of leeway in their interpretation of the law. Under a radical nullification instruction, jurors show heightened sympathy with the defendant and are more likely to find the defendant not guilty by reason of self defense. However, applying an expected utility logic to the jury decision-making task requires that jurors choose not to find the woman guilty of homicide because they find the probability of a negative consequence associated with that outcome lower in value than the probability of a negative consequence associated with the guilty outcome. Only when the jurors are free to choose the verdict unencumbered by the constraints of the law do they allow themselves to feel sympathy for the victim of spousal abuse.

What might that outcome be that is so aversive that jurors are willing to distort the law of self-defense to eliminate the defendant's responsibility for her husband's death? If we are willing to attach value to anticipated emotion, there is the interesting possibility that jurors who feel sympathy for the defendant are trying to avoid the negative emotion that they would feel if they were responsible for convicting a woman toward whom they felt such strong emotions. Under the guiding light of emotion infused expected utility theory, we find that rational choice can account for what might appear at first as an irrational choice. Future research that adopts this type of affective rational choice model has the potential to add greatly to our understanding of legal decision making in a variety of dispute resolution contexts, including the typical jury decision-making task, which legal psychologists study so commonly.

Second, the use of expected utility theory and the lens model to depict legal judgment and decision-making models points out the possible roles of affect for future research (see also Maroney, 2006). We maintain that using a general model depiction of the decision or judgment task makes apparent the potential mediating and moderating roles of affect as decision makers anticipate or experience it at the time of the judgment. For example, Wenzel (2004)made use of survey data that Braithwaite collected from Australian taxpayers to demonstrate that strong external social norms coupled with weak internalized values can increase the deterrent value of se- 
vere sanctions. Nonetheless, these data offer very little in the way of psychological explanation, other than stating that potential offenders with strong social norms held externally should act to avoid the shame and embarrassment that violating the law would bring. However, examining the problem as one of the anticipated affective consequences suggests that under these conditions taxpayers attach special significance to the detection of cheating because of the negatively valenced emotions that they anticipate experiencing as probable outcomes of their choice to cheat. The affective version of the expected utility model raises the interesting possibility that anticipated embarrassment or shame is a mediator in the deterrent effect of the high likelihood of severe consequences for illegal behavior. Understanding this mediation effect in choices that people make with regard to law violation could be an important factor in developing interventions to increase compliance with tax laws and other self-guided legal judgments.

Similarly, the application of the lens model to legal judgment tasks raises some interesting moderator effects that experienced emotions could play in legal decision making. For example, Forgas et al. (2005) demonstrated that one moderator of the misinformation effect in eyewitness identification is the emotion that the witnesses experience when they are exposed to suggestive information. Witnesses experiencing positive emotions show more evidence of the misinformation effect than do those experiencing negative affect. By itself, this is an interesting finding but depicting the misinformation paradigm as a lens model problem also points out that the explanation for the moderating effect of affective valence could operate in either of the two ways. First, it could alter the observers' abilities to estimate the ecological validity of the cues (i.e., whether they are related to the actual experienced event) or it could influence the way in which the witness integrates a number of cues properly to produce an accurate description of the crime scene. The use of the lens model points out some specific mechanisms that might be responsible for the role of emotion as a moderator for the misinformation effect.

Finally, as we have pointed out there are a number of theoretical accounts of the ways in which emotion might generally influence choice and judgment, including the role of anticipated affect (Mellers, 2000; Mellers, Schwartz, Ho, et al., 1997; Mellers et al., 1999), experienced emotion (Shiv \& Fedorikhin, 2002; Tiedens \& Linton, 2001), affect as information (Schwarz, 1990; Schwarz \& Clore, 1983; Slovic et al., 2002), and affect as a memory prime (19). General models of choice and judgment such as the two illustrated here are flexible enough to accommodate a number of affective theories. In the early stages of studying the role of affect in legal decision making, this flexibility invites researchers to try out different affective theories to help explain the outcomes of legal choice or judgment. Although the degrees of freedom that allow the use of different theories of emotion to account for legal choices and judgments may dry up as more and more data limit the ability of these models to provide parsimonious explanations of legal judgments, at the current stage of analysis the flexibility of the more general models offers heuristic research paradigms.

\section{Conclusion}

For too long psychologists studying legal decision making have ignored the obvious and insisted upon studying eyewitness identification, jury decision making, compliance with the law, judicial decision making, and many other types of legal judgments, as if they occurred in the absence of emotion and motivation. As a result, there are few examples of empirical investigations of law and legal process that make use of either general or specific theories of emotion applied to judgment and decision making. In this article, we have pointed out how we can adopt existing models of judgment and decision making that are familiar to legal psychologists to study the role of emotion in legal contexts. Using three recently published examples of legal decision making that 
find results that, at least, suggest the importance of anticipated and experienced emotions, we have shown how modifying the rational choice and lens models to accommodate these theories offers important insights into legal decision making and judgment. We believe that the usefulness of this approach to emotions in the law is limited only by the creativity of the psycholegal scholar and hope that this exercise will encourage others to include affective constructs, measures, and manipulations in their legal decision-making research.

\section{References}

Alhakami, A. S., \& Slovic, P. (1994). A psychological study of the inverse relationship between perceived risk and perceived benefit. Risk Analysis, 14, 1085-1096.

Batra, R., \& Stayman, D. M. (1990). The role of mood in advertising effectiveness. Journal of Consumer Research, 17, 203-214.

Bless, H., Bohner, G., Schwarz, N., \& Strack, F. (1990). Mood and persuasion: A cognitive response analysis. Personality and Social Psychology Bulletin, 16, 331-345.

Bornstein, B. H., \& Nemeth, R. J. (1999). Jurors' perception of violence: A framework for inquiry. Aggression and Violent Behavior, 4, 77-92.

Bornstein, B. H., \& Wiener, R. L. (2006). Introduction to the special edition on emotion in legal judgment and decision making. Law and Human Behavior, 30.

Braithwaite, J. (2000). The community hopes, fears and actions survey. Canberra: centre for Tax System Integrity, Research School of Social Sciences, Australian National University.

Brewer, M. B., \& Hewstone, M. (Eds.) (2004). Emotion and motivation. Malden, MA: Blackwell Publishing Co.

Browne, A. (1987). When battered women kill. New York: Free Press.

Brunswik, E. (1952). The conceptual framework of psychology. Chicago, IL: University of Chicago Press.

Crocker, P. (1985). The meaning of equality for battered women who kill men in self-defense. Harvard Women's Law Journal, 8, 121-153.

Cutler, B. L., \& Penrod, S. D. (1995). Mistaken identification: The eyewitness, psychology, and the law. New York: Cambridge University Press.

Deffenbacher, K. A., Bornstein, B. H., Penrod, S. D., \& McGorty, E. K. (2004). A meta-analytic review of the effects of high stress on eyewitness memory. Law and Human Behavior, 28, 687-706.

Dobash, R. E., \& Dobash, R. P. (1984). The nature and antecedents of violent events. British Journal of Criminology, 24, 269-288.

Eagly, A. H., \& Chaiken, S. (1993). The psychology of attitudes. Orlando, FL: Harcourt Brace Jovanovich College Publishers.

Faragher v. City of Boca Raton (1998). 118 S.Ct. 2275.

Feigenson, N., \& Park, J. (2006). Emotions and attributions of legal responsibility and blame: a research review. Law and Human Behavior, 30(2).

Fischer, K., Vidmar, N., \& Ellis, R. (1993). The culture of battering and the role of mediation in domestic violence cases. SMU Law Review, 46, 2117-2176.

Finucane, M. L., Alhakami, A., Slovic, P., \& Johnson, S. M. (2000). The affect heuristic in judgments of risks and benefits. Journal of Behavioral Decision Making, 13, 1-17.

Forgas, J. P. (1995). Mood and judgement: The affect infusion model (AIM). Psychological Bulletin, 117, 39-66.

Forgas, J. P., Bower, G. H., \& Krantz, S. (1984). The influence of mood on perceptions of social interactions. Journal of Experimental Social Psychology, 20, 497-513.

Forgas, J. P., Bower, G. H., \& Moyan, S. J. (1990). Praise or blame? Affective influences on attributions for achievement. Journal of Personality and Social Psychology, 59, 809-818.

Forgas, J. P., Laham, S. M., \& Vargas, P. T. (2005). Mood effects on eyewitness memory: Affective influences on susceptibility to misinformation. Journal of Experimental Social Psychology, 41, 574-588.

Gerrie, M. P., Garry, M., \& Loftus, E. F. (2005). False memories. In N. Brewer \& K. D. Williams (Eds.), Psychology and law: An empirical perspective (pp. 222-253). New York: Guilford.

Grasmick, H. G., \& Bursik, R. J. (1990). Conscience, significant others, and rational choice: Extending the deterrence model. Law and Society Review, 24, 837-861. 
Grasmick, H. G., \& Scott, W. J. (1982). Tax evasion and mechanisms of social control: A comparison with grand and petty theft. Journal of Economic Psychology, 2, 213-230.

Hammond, K. R. (2000a). Coherence and correspondence theories in judgment and decision making. In T. Connolly, H. R. Arkes, \& K. R. Hammond (Eds.), Judgment and decision making: An interdisciplinary reader (pp. 53-65). New York: Cambridge University Press.

Hammond, K. R. (2000b). Judgments under stress. New York: Oxford University Press.

Hastie, R., \& Dawes, R. M. (2001). Rational choice in an uncertain world. Thousand Oaks, CA: Sage Publications.

Horowitz, I. A. (1988). Jury nullification: the impact of judicial instructions, arguments, and challenges on jury decision making. Law and Human Behavior, 12, 439-453.

Horowitz, I. A., Kerr, N. L., Park, E. S., \& Gockel, C. (2006). Chaos in the courtroom reconsidered: Emotional bias and juror nullification. Law and Human Behavior, 30, this volume.

Isen, A. (1993). Positive affect and decision making. In M. Lewis \& J. M. Haviland (Eds.), Handbook of emotions (pp. 261-277). New York: Guilford Press.

Kinsey, K. A., \& Grasmick, H. G. (1993). Did the tax reform act of 1986 improve compliance? Three studies of pre- and post-TRA compliance attitudes. Law and Policy, 15, 239-325.

Korokbin, R. B., \& Ulen, T. S. (1998). Efficiency and equity: What can be gained by combining Coase and Raw1s? Washington Law Review, 73, 329-347.

Korobkin, R. B., \& Ulen, T. S. (2000). Law and behavioral science: Removing the rationality assumption from law and economics. California Law Review, 88, 1051-1144.

Landes, W. M., \& Posner, R. A. (1987). The economic structure of tort law. Cambridge, MA: Harvard University Press.

Lerner, J. S., \& Keltner, D. (2000). Beyond valence: Toward a model of emotion-specific influences on judgment and choice. Cognition and Emotion, 14, 473-493.

Lerner, J. S., \& Keltner, D. (2001). Fear, anger, and risk. Journal of Personality and Social Psychology, 81, $146-159$.

Lerner, J. S., Gonzalez, R. M., Small, D. A., \& Fischhoff, B. (2003). Effects of fear and anger on perceived risks of terrorism: A national field experiment. Psychological Science, 14, 144-150.

Lindsay, D. S., \& Johnson, M. K. (1989a). The eyewitness suggestibility effect and memory for source. Memory and Cognition, 17, 349-358.

Lindsay, D. S., \& Johnson, M. K. (1989b). The reversed eyewitness suggestibility effect. Bulletin of the Psychonomic Society, 27, 111-113.

Loewenstein, G. F., Weber, E. U., Hsee, C. K., \& Welch, N. (2001). Risk as feelings. Psychological Bulletin, 127, 267-286.

Loftus, E. F. (1979). Reactions to blatantly contradictory information. Memory and Cognition, 7, 368-374.

Loftus, E. F., Donders, K., Hoffman, H. G., \& Schooler, J. W. (1989). Creating new memories that are quickly accessed and confidently held. Memory and Cognition, 17, 607-616.

Mackie, D. M., Asuncion, A. G., \& Rosselli, F. (1992). The impact of positive affect on persuasion processes. In

M. S. Clark's (Ed.), Emotion and social behavior (pp. 247-270). Thousand Oaks, CA: Sage Publications.

Mackie, D. M., \& Worth, L. T. (1989). Processing deficits and the mediation of positive affect in persuasion. Journal of Personality and Social Psychology, 57, 27-40.

Maroney, T. A. (2006). Law and emotion: A proposed taxonomy of an emerging field. Law and Human Behavior, 30(2).

McCloskey, M., \& Zaragoza, M. (1985). Misleading postevent information and memory for events: arguments and evidence against memory impairment hypotheses. Journal of Experimental Psychology, 114, 1-16.

Mellers, B. A. (2000). Choice and the relative pleasure of consequences. Psychological Bulletin, 126, 910-924.

Mellers, B. A., Schwartz, A., Ho, K., \& Ritov, I. (1997). Decision affect theory: emotional reactions to the outcomes of risky options. Psychological Science, 8, 423-429.

Mellers, B. A., Schwartz, A., \& Ritov, I. (1999). Emotion-based choice. Journal of Experimental Psychology: General, 128, 332-345.

Monahan, J., \& Walker, L. (2002). Social science in law: Cases and materials (5th ed.). Mineola, NY: Foundation Press.

Murray, N., Surjan, H., Hirt, E. R., \& Surjan, M. (1990). The influence of mood on categorization: A cognitive flexibility interpretation. Journal of Personality and Social Psychology, 59, 411-425.

Parrott, W. G., \& Sabini, J. (1990). Mood and memory under natural conditions: evidence for mood incongruent recall. Journal of Personality and Social Psychology, 59, 321-336. 
Petty, R. E., Gleicher, F., \& Baker, S. (1991). Multiple roles for affect in persuasion. In J.P. Forgas (Ed.), Emotion and social judgments (pp. 181-200). Elmsford, NY: Pergamon Press.

Pezdek, K., \& Roe, C. (1995). The effect of memory trace strength on suggestibility. Journal of Experimental Child Psychology, 60, 116-128.

Posner, R. (1997). Are we one self or multiple selves? Implications for law and public policy. Legal Theory, 3 , 23-39.

Rabidue v. Osceola Refining Co. (1986). 805 F.2d 611 (6th Cir. 1986).

Reyna, V. F., \& Loyd, F. (1997). Theories of false memory in children and adults. Learning and Individual Differences, 9, 95-123.

Ross, D. F., Read, J. D., \& Toglia, M. P. (1994). Adult eyewitness testimony: Current trends and developments. New York: Cambridge University Press.

Schneider, E. M. (1986). The dialectic of rights and politics: The perspective from the women's movement. New York University Law Review, 61, 589-651.

Schuller, R. A., \& Hastings, P. A. (1996). Trials of battered women who kill: The impact of alternative forms of expert evidence. Law and Human Behavior, 20, 167-187.

Schuller, R. A., \& Rzepa, S. (2002). Expert testimony pertaining to battered woman syndrome: Its impact on jurors' decisions. Law and Human Behavior, 26, 655-673.

Schwarz, N. (1990). Feelings as information: Informational and motivational functions of affective states. In E. T. Higgins \& R. M. Sorrentino (eds.), Handbook of motivation and cognition: Foundations of social behavior (Vol. 2, pp. 527-561). New York: Guilford Press.

Schwarz, N., Bless, H., \& Strack, F. (1991). Ease of retrieval as information: Another look at the availability heuristic. Journal of Personality and Social Psychology, 61, 195-202.

Schwarz, N., \& Clore, G. L. (1983). Mood, misattribution and judgments of well-being: Informative and directive functions of affective states. Journal of Personality and Social Psychology, 45, 513-523.

Scott, W. J., \& Grasmick, H. G. (1981). Deterrence and income tax cheating: Testing interaction hypotheses in utilitarian theories. Journal of Applied Behavioral Science, 17, 395-408.

Shiv, B., \& Fedorikhin, A. (2002). Spontaneous versus controlled influences of stimulus-based affect on choice behavior. Organizational Behavior and Human Decision Processes, 87, 342-370.

Sinclair, R. C., \& Mark, M. M. (1992). The influence of mood state on judgment and action: Effects on persuasion, categorization, social justice, person perception, and judgmental accuracy. In L. L. Martin \& A. Tesser (eds.), The construction of social judgments (pp. 165-193). Hillsdale, NJ: Erlbaum.

Slovic, P., Finucane, M., Peters, E., \& MacGregor, D. G. (2002). The affect heuristic. In T. Gilovich, D. Griffin, \&

D. Kahneman (Eds.), Heuristics and biases: the psychology of intuitive judgment (pp. 397-420). New York: Cambridge University Press.

Smith, C. A., \& Ellsworth, P. C. (1985). Patterns of cognitive appraisal in emotion. Journal of Personality and Social Psychology, 48, 813-838.

Stein, N. L., Ornstein, P. A., Tversky, B., \& Brainerd, C. (Eds.) (1997). Memory for everyday and emotional events. Mahwah, NJ: Erlbaum.

Tiedens, L. Z., \& Linton, S. (2001) Judgment under emotional certainty and uncertainty: The effects of specific emotions on information processing. Journal of Personality and Social Psychology, 81, 973-988.

Varma, K. N., \& Doob, A. N. (1998). Deterring economic crimes: The case of tax evasion. Canadian Journal of Criminology, 40, 165-184.

Voss, A., \& Wiener, R. L. (March, 2006). Feeling your way to a decision: The role of emotion in perceptions of sexual harassment. Paper presented at the Annual American Psychology and Law Meeting (Division 41 of APA), St. Petersburg, FL.

Walker, L. A. (1984). Battered women, psychology, and public policy. American Psychologist, 39, 1178-1182.

Wegener, D. T., Petty, R. E., \& Smith, S. M. (1995). Positive mood can increase or decrease message scrutiny: The hedonic contingency view of mood and message processing. Journal of Personality and Social Psychology, 69, 5-15.

Wells, G. L., \& Loftus, E. F. (2003). Eyewitness memory for people and events. In A. M. Goldstein \& N. J. Hoboken (Eds.), Handbook of psychology: Forensic psychology (Vol. 11, pp. 149-160). NJ: Wiley.

Wenzel, M. (2002). The impact of outcome orientation and justice concerns on tax compliance: The role of taxpayers' identity. Journal of Applied Psychology, 87, 629-645.

Wenzel, M. (2004). An analysis of norm processes in tax compliance. Journal of Economic Psychology, 25, $213-228$.

Worth, L. T., \& Mackie, D. M. (1987). Cognitive mediation of positive affect in persuasion. Social Cognition, 5 , $76-94$. 